\title{
IMPlementing split Regimen OVEr Single dose using a Plan-Do- Study-Act approach (IMPROVES study)
}

\section{다)(우우}

\section{Authors}

Giuseppe Vanella ${ }^{1}$, Cesare Hassan ${ }^{2}$, Mario De Bellis ${ }^{3}$, Maxemiliano Giardini ${ }^{4}$, Enrico Grasso ${ }^{5}$, Francesco Laterza ${ }^{6}$, Ottaviano Tarantino ${ }^{7}$, Emilio Di Giulio ${ }^{1}$

Institutions

1 Sant'Andrea Hospital, Faculty of Medicine and Psychology, Sapienza University of Rome, Rome, Italy

2 Nuovo Regina Margherita Hospital, Rome, Italy

3 Istituto Nazionale Tumori - IRCCS - Fondazione G. Pascale, Naples, Italy

4 Urbino Hospital, Urbino, Italy

5 Tor Vergata University, Rome, Italy

6 Gabriele d'Annunzio University and Foundation, Chieti, Italy

7 San Giuseppe Hospital, Empoli, Italy

submitted 9.5.2019

accepted after revision 27.6.2019

Bibliography

DOI https://doi.org/10.1055/a-0996-8118 |

Endoscopy International Open 2019; 07: E1457-E1467

(c) Georg Thieme Verlag KG Stuttgart · New York

eISSN 2196-9736

Corresponding author

Emilio Di Giulio, MD, Sapienza University of Rome, Faculty of Medicine and Psychology, Sant'Andrea University Hospital, Via di Grottarossa, 1035-1039, 00189 Rome, Italy Fax: +39-06-33776692

emilio.digiulio@uniroma1.it

\section{Supplementary Material}

Online content viewable at:

https://doi.org/10.1055/a-0996-8118

\section{ABSTRACT}

Background and aims A split-dose regimen for colonoscopy is recommended by international guidelines, but its adoption is still suboptimal. Our aim was to assess whether a Plan-Do-Study-Act approach (PDSA), a scientific method promoting quality improvement, would be able to improve adherence to a split-dose regimen, and to identify factors influencing its adoption.

Methods This study consisted of three phases: Cycle 1: a cross-sectional assessment of split-dose adherence in consecutive outpatients/inpatients undergoing colonoscopies in 74 Italian centers; Educational intervention: regional meetings with literature review, analysis of Cycle 1 data, and discussion on corrective measures; local diffusion of educational material and tools for improvement; Cycle 2: reassessment of split-dose adherence after spontaneous local interventions. Demographic, clinical, and procedural variables were systematically collected. Multivariate logistic regression was used to identify predictors of split-dose adoption.

Results In total, 8213 patients (mean age $=60.29$ years $(S D=13.58)$, men $=54 \%$, outpatients $=88.4 \%)$ were enrolled between 2013 and 2016 (Cycle $1=4189$ patients and Cycle $2=4024$ patients). Split-dose adoption rose from $29.1 \%$ in Cycle 1 to $51.1 \%$ in Cycle $2(P<0.0001)$, and being enrolled in Cycle 2 independently predicted split-dose adherence $(\mathrm{OR}=2.9 ; 95 \% \mathrm{Cl} 2.6-3.3)$. The adoption improved in all time slots, including colonoscopies scheduled before 0930. The main corrective measures were: rescheduling of colonoscopies after 0930 (between 0930 and 1130: OR= 2.6; $95 \% \mathrm{Cl} 2.3-3.1$; after 1130 : $\mathrm{OR}=7$; $95 \% \mathrm{Cl} 5.9-8.4$ ); the cleansing regimen communicated by the Endoscopy unit (via form: $O R=1.6 ; 95 \% \mathrm{Cl} 1.3-1.9$; via visit: $O R=2.1$; $95 \% \mathrm{Cl} 1.7-2.5)$; a decrease in the use of deep sedation $(\mathrm{OR}=2 ; 95 \% \mathrm{Cl} 1.7-2.5)$.

Conclusions An educational intervention with observation-driven corrections through a PDSA approach was able to substantially increase the adoption of a split-dose regimen.

Clinical.Trials.gov

NCT03581175

TRIAL REGISTRATION: Single-Center, Observational, Crosssectional study NCT03581175 at clinicaltrials.gov 


\section{Introduction}

The split-dose regimen has demonstrated its superiority [1, 2] over the day-before regimen in determining a better colon cleansing and, therefore, for the detection of clinically relevant neoplasia $[3,4]$. For these reasons, it is now considered by international guidelines to be the standard for bowel preparation for colonoscopies, along with the same-day regimen for afternoon colonoscopies [5, 6]. However, its application is suboptimal [7], and this may account for the suboptimal rates of adequate cleansing achieved by some centers, compared with the standards required by ESGE and ASGE $[8,9]$.

Barriers precluding the prescription of a split-dose regimen have been explored in a few studies $[10,11]$, mainly in the setting of auditing of current practice. Conversely, corrective measures aiming at changing the practice have been prospectively tested in very few, small and selected cohorts [12-14], and rarely with split-dose regimen adoption as the principal outcome [12].

One scientific method involved in continuous quality improvement is the Plan-Do-Study-Act approach (PDSA) $[15,16]$. This approach is characterized by cycles in which an initial analysis of a problem and of desired ameliorations determines observation-driven corrections which are verified through intermediate field tests and thereafter audited, to reinforce positive changes and discard ineffective ones [17]. The philosophy behind this method is that quality improvement can be effectively achieved only when it can be described as a process in which ameliorations are linked to indicators that can be measured. PDSA has already demonstrated its utility in optimizing bowel cleansing $[13,14,18]$, but without specifically addressing an increase in split-dose regimen adoption, and mainly in very selected cohorts.

The aim of this study was to use the PDSA approach to improve split-dose regimen adoption among several Italian endoscopic facilities, and to use the collected data to analyze factors favoring and limiting this adoption.

\section{Methods}

A multicentre prospective study on consecutive colonoscopies executed in two different time frames was performed in 74 endoscopic centers in Central Italy selected by regional boards of the Italian national endoscopy society. Data were collected through an electronic form and were stored and managed by independent data managers.

The study was approved by the ethics committee of Sant' Andrea Hospital - Sapienza University of Rome (protocol $\mathrm{n}$. 10791/2013, approved 09/16/2013). An informed consent was obtained for every participant. The study has been registered in ClinicalTrials.gov (Identifier: NCT03581175).

Following the PDSA approach, the study was divided into three phases: Cycle 1, one educational phase, and Cycle 2.

\section{Cycle 1}

During this part of the study, between September 2013 and February 2014, no variation was made to routine practice in regimen choice and communication or in the organization of the service, and colonoscopy practice was analyzed, with particular interest for bowel cleansing prescription, its adoption, and its outcomes.

After a literature review, a questionnaire was structured through expert agreement of the coordinating committee. Before colonoscopy, a trained investigator filled in the questionnaire for every outpatient or inpatient undergoing the exam. No exam was a priori excluded, provided that a complete colonoscopy with full bowel cleansing was planned, regardless of the product or regimen used. Therefore, the only exclusion criteria were: 1) the inability of the patients to comprehend the study and to agree with their inclusion; 2) the endoscopic examination being planned without a complete bowel cleansing (e.g. sigmoidoscopy prepared by enema). No patient comorbidity determined exclusion from the study if a full bowel cleansing regimen was prescribed and at least initiated.

The split-dose regimen was defined as a regimen in which one fraction of the product was consumed the day before the exam and the other one on the examination day, while in daybefore and in same-day regimens, the whole product was consumed, respectively, on the day before or on the same day as the examination.

Demographic, clinical, and procedural variables were systematically registered through an anonymous electronic case report form (for the complete list of variables explored, see Supplementary Material, Statement 1).

Preparation-to-colonoscopy time was calculated as the interval between the self-reported last dose of preparation consumed and the effective colonoscopy initiation time. The planned (and not the effective) initiation time was conversely used in analyses evaluating the role of preprocedural variables in predicting split-dose regimen adoption.

\section{Educational phase}

After all centers had concluded Cycle 1, independent data managers analyzed the collected data and provided each center with local and general statistics. Thereafter, meetings at a regional level were organized every 3 months to: discuss the collected data; query data to identify hypothetical barriers limiting the adoption of the split-dose regimen; review available evidence on the efficacy and tolerability of the split-dose regimen; discuss possible areas of intervention. After each center had attended one regional meeting, in September 2014, local facilities received a DVD containing a motivational letter, educational material (including digital presentation material), an implementation manual (including compulsory local checkpoints with regard to diffusion of educational material and internal meetings), freely customizable module samples and indications for self-reporting of local ameliorations (see $>$ Table 1 ). No central coordination of corrective measures was undertaken, but each endoscopic unit was free to make any desired adjustment, in light of the interim analysis and ongoing auditing and discus- 
- Table 1 Improvement process, PDSA-derived barriers and self-reported local interventions.

Aim: Implementation of split-dose regimen adoption

Tools (DVD):

- Local and regional statistics

- Motivational letter from study coordinators

- Implementation manual

- Recommendations from guidelines

- Reference list of published evidence

- Identified problems (during Cycle 1 and earlier regional meetings)

- Discussed areas of intervention

- Pre-ordinated compulsory checkpoints

- Indications on self-reporting of ameliorations

- Digital presentation material

- Checklists to screen for patients requiring special consideration

- Samples of customizable modules for patients

\begin{tabular}{|c|c|c|}
\hline $\begin{array}{l}\text { Identified problem }(\mathrm{P}) \text { | } \\
\text { Area of intervention }\end{array}$ & $\begin{array}{l}\text { Improvement checkpoints (C) } \\
\text { (date of execution/completion required) }\end{array}$ & Self-reported ameliorations (A) \\
\hline P1. Staff training & $\begin{array}{l}\text { C1. Diffusion of educational material } \\
\text { C2. Staff examination of educational } \\
\text { material } \\
\text { C3. Educational meeting with endoscopy } \\
\text { staff } \\
\text { C4. Educational letter to hospital wards }\end{array}$ & $\begin{array}{l}\text { A1. Dissemination of guidelines and discussion of published evi- } \\
\text { dence with regard to efficacy, safety, and tolerability of split- } \\
\text { dose regimens }\end{array}$ \\
\hline P2. Patient education & None & $\begin{array}{l}\text { A2. Revision of written instructions, explicitly mentioning split- } \\
\text { dose regimens, their efficacy, their tolerability, and the ab- } \\
\text { sence of significant increase in adverse events (especially while } \\
\text { reaching the hospital) } \\
\text { A3. Modules with customizable time for the consumption of the } \\
\text { second dose of preparation } \\
\text { A4. Differentiation of preparation regimens according to colonos- } \\
\text { copy time (including modification of split-dose regimens with } \\
\text { a } 75 \% / 25 \% \text { split delivery) } \\
\text { A5. Dedicated staff "navigating" the patients through compre- } \\
\text { hension of their regimen }\end{array}$ \\
\hline $\begin{array}{l}\text { P3. Information provided } \\
\text { by independent reserva- } \\
\text { tion systems }\end{array}$ & $\begin{array}{l}\text { C5. Educational meeting with staff of the } \\
\text { independent reservation system } \\
\text { C6. Diffusion of checklists }\end{array}$ & $\begin{array}{l}\text { A6. Implementation of endoscopy-coordinated prescription of } \\
\text { bowel cleansing } \\
\text { A7. Diffusion of checklists to select patients needing to be "navi- } \\
\text { gated" by endoscopy staff } \\
\text { A8. Diffusion of checklists to select patients to allocate to late- } \\
\text { morning or afternoon colonoscopies }\end{array}$ \\
\hline P4.Colonoscopy scheduling & None & A9. Rescheduling of colonoscopies avoiding early-morning slots \\
\hline $\begin{array}{l}\text { P5. Involvement of the anes- } \\
\text { thesiologist }\end{array}$ & None & $\begin{array}{l}\text { A10. Discussion of anesthesiological guidelines and evidence on } \\
\text { residual gastric volume after split-dose regimens } \\
\text { A11. Increased awareness in the use of deep sedation, with limited } \\
\text { access }\end{array}$ \\
\hline
\end{tabular}

PDSA, Plan-Do-Study-Act approach.

sion, according to a Plan-Do-Study-Act approach (see Supplementary Fig.1). Cycle 2 was initiated only after every center had completed local mandatory checkpoints and attended at least one additional regional meeting. No specific intervention was assigned to individual study participants in either cycle, and who were managed according to current practice.

\section{Cycle 2}

Between December 2015 and February 2016, colonoscopy practice was again monitored through the same initial questionnaire, looking for improvements.

\section{Sample size}

Due to the absence of epidemiological data on split-dose regimen adoption in Italy when the study was conceived, no formal sample size calculation was planned, but since a generalizable result was targeted, we decided to include more than 70 centers and at least 3500 patients per cycle, corresponding overall to a minimum of 7000 patients (i. e. 100 per center).

Enrolment in Cycle 1 and Cycle 2 closed after reaching the minimum number of required patients, which was checked on a weekly basis. 
- Table 2 Characteristics of patients included in Cycle 1 and Cycle 2.

\begin{tabular}{|c|c|c|c|}
\hline Variable & Cycle $1(n=4189)$ & Cycle $2(n=4024)$ & $P$ value \\
\hline Males, n (\%) & $2226(53.1 \%)$ & $2206(54.8 \%)$ & 0.1263 \\
\hline Mean age (SD), years & $60.38(13.66)$ & $60.20(13.51)$ & 0.5407 \\
\hline Education, n (\%) & & & 0.2031 \\
\hline - Primary & $868(20.7 \%)$ & $797(19.8 \%)$ & \\
\hline - Secondary I & $1144(27.3 \%)$ & $1104(27.4 \%)$ & \\
\hline - Secondary II & $1531(36.5 \%)$ & $1437(35.7 \%)$ & \\
\hline - Degree or above & $646(15.4 \%)$ & $686(17.0 \%)$ & \\
\hline Type of patient, n (\%) & & & 0.1225 \\
\hline - Outpatients & $3680(87.8 \%)$ & $3579(88.9 \%)$ & \\
\hline - Inpatients & $509(12.2 \%)$ & $445(11.1 \%)$ & \\
\hline Time to reach the hospital (outpatients only), $\mathrm{n}(\%)^{1}$ & & & 0.8383 \\
\hline - $<1 \mathrm{~h}$ & $3222(87.6 \%)$ & $3140(87.7 \%)$ & \\
\hline . $1-2 \mathrm{~h}$ & $416(11.3 \%)$ & $394(11.0 \%)$ & \\
\hline . $>2 \mathrm{~h}$ & $42(1.1 \%)$ & $45(1.3 \%)$ & \\
\hline Presence of comorbidities, n (\%) & $1625(38.8 \%)$ & $1737(43.2 \%)$ & $<0.0001^{2}$ \\
\hline First colonoscopy, n (\%) & $2233(53.3 \%)$ & 2282 (56.7\%) & $0.0019^{2}$ \\
\hline $\begin{array}{l}\text { SD, standard deviation. } \\
{ }^{1} \text { Percentages are referred to the total number of outpatier } \\
2 P<0.05 \text {. }\end{array}$ & & & \\
\hline
\end{tabular}

\section{Statistical analysis}

The primary outcome of this study was the change in split-dose regimen adoption rate before (Cycle 1 ) and after (Cycle 2 ) the observation-driven implementation phase (PDSA). The secondary outcome was to analyze several patient-, center-, and procedure-related variables looking for differences between Cycle 1 and Cycle 2, and searching for any predicting values on different outcomes in multivariate models, the principle of which analyzed the adoption of split-dose versus day-before modality as the dependent variable; for this model, we a priori decided to consider only morning colonoscopies, since this is the setting for which the split-dose procedure is recommended, the setting in which its use is more challenging, and because a number of centers included did not perform afternoon colonoscopies. Other models reported as supplemental material considered the following dependent variables: the adoption of a regimen other than the day-before for afternoon colonoscopies; patients' willingness to repeat the preparation; endoscopist satisfaction; cleansing adequacy in the left and right colon.

Continuous variables were reported as means (and standard deviations) while categorical variables were reported as frequencies (proportions). Some continuous variables were categorized (see Supplementary Material: Statement 2).

Variables were reported separately for Cycle 1 and 2, and were compared using a Student's $t$ test for continuous variables and a chi-squared test for categorical variables.
For each multivariate logistic regression model, a stepwise selection of independent variables was made using a $P$-to-enter $<0.05$, and a $P$-to-stay $<0.1$. The results are reported as odds ratios (OR), $95 \%$ confidence intervals $(\mathrm{Cl})$, and $P$ values.

A $P$ value of $<0.05$ was considered to be statistically significant.

\section{Results}

In total, 8267 patients were enrolled between February 2013 and February 2016 in 74 endoscopic centers in Central Italy (93.2\% public vs $6.8 \%$ private facilities; $23 \%$ academic institutions). The uploading process through the electronic system was completed for 8213 patients (99.3\%) who were finally considered for the study. Data on cleansing regimen were available for $100 \%$ of patients included, since the lack of this variable was considered to be an incomplete upload, and the patient consequently excluded.

\section{Characteristics of patients}

Among the patients included, mean age was 60.3 (13.6) years, $54 \%$ were male and $88.4 \%$ were outpatients. In total, 4189 patients were enrolled in Cycle 1, while 4024 were enrolled in Cycle 2. Characteristics of patients included in the two cycles are presented and compared in $>$ Table 2.

The two groups were homogeneous in terms of demographic variables. However, in Cycle 2, slightly more patients present- 


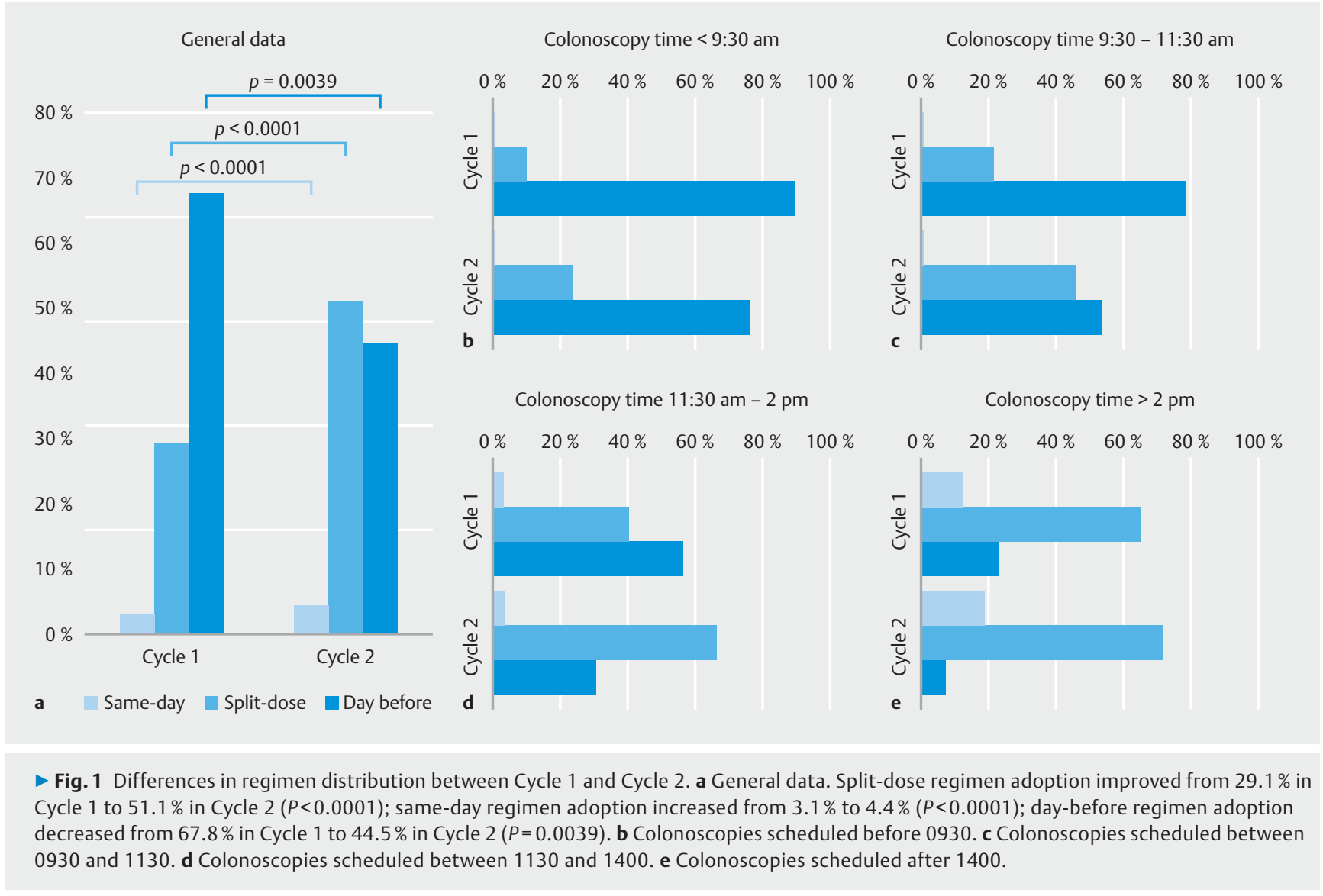

ed comorbidities (43.2\% vs $38.8 \%, P<0.0001)$ and were at their first colonoscopy (56.7\% vs $53.3 \%, P=0.0019)$.

\section{Efficacy of PDSA approach: differences between Cycle 1 and Cycle 2}

Regimen adoption. Split-dose and same-day regimen adoption significantly increased in Cycle 2 compared to Cycle 1 (55.5\% vs 32.2\% [P<0.0001], respectively), while there was a significant reduction in the adoption of a day-before regimen (44.5\% vs 67.8\%; $P<0.0001)$. Separate data for split-dose and same-day regimens are provided in Fig. 1 a and $>$ Table 3 . When colonoscopies were stratified according to scheduled time, in Cycle 2, an improvement in split-dose adoption was achieved in every time slot $(P<0.0001$ for all), including colonoscopies planned before 0930 ( $\mathbf{F i g} . \mathbf{1 b}$ ). However, in Cycle 2 , the split-dose regimen became the preferred cleansing regimen only for colonoscopies planned after 1130 ( $>$ Fig.1 d), while the day-before regimen remained the preferred solution for colonoscopies planned before 1130 ( $\mathbf{F i g . 1 b}, \mathbf{c}$ ). The adoption of the same-day regimen significantly increased only for colonoscopies planned after 1400 ( $\triangleright$ Fig. 1e), even if the preferred regimen for afternoon colonoscopies was (in Cycle 1) and confirmed to be (in Cycle 2) the split-dose regimen. The higher rate of split-dose regimen adoption also decreased the preparation-to-colonoscopy time (the so-called "runway time") reducing the proportion of patients for whom this was $\geq 6$ hours from $75.3 \%$ of Cycle 1 to $56.4 \%$ of Cycle $2(P<$ 0.0001 ; see $>$ Table 3 and Supplementary Fig. 2).

PDSA-derived local interventions between Cycle 1 and Cycle 2. According to the PDSA approach, each endoscopy unit was invited to improve its local split-dose adoption rate using information acquired during the educational intervention (through educational meetings and the DVD) and based on the analysis of Cycle 1 data, on the review of published evidence, and on the discussion of hypothetical corrections applicable to single facilities.

- Table 1 details the improvement process, analyzing the main problems and areas of intervention identified through the ongoing discussion and the main ameliorations self-reported by single centers.

The complete spectrum of patient-, regimen-, and procedure-related variables explored (and compared) in Cycle 1 and 2 are reported in $>$ Table 2 , $>$ Table 3 , and $>$ Table 4.

\section{Multivariate analyses}

Split-dose regimen adoption. A multivariate logistic regression model was built to evaluate the variables associated with the adoption of a split-dose regimen (see $>$ Table 5 ). A colonoscopy scheduled before 0930 significantly reduced the probability of a split-dose regimen being prescribed, while there was an almost 3-fold and more than 7-fold increase in the probability when colonoscopy was planned between 0930 and $1130(\mathrm{OR}=$ $2.6[\mathrm{Cl} 2.3-3.1])$ and between 1130 and $1400(\mathrm{OR}=7[\mathrm{Cl} 5.9-$ 
- Table 3 Differences in bowel cleansing regimen between Cycle 1 and Cycle 2.

\begin{tabular}{|c|c|c|c|}
\hline Variable & Cycle $1(n=4189)$ & Cycle $2(n=4024)$ & $P$ value \\
\hline Regimen, n (\%) & & & $<0.0001^{1}$ \\
\hline - Day before & $2840(67.8 \%)$ & $1790(44.5 \%)$ & \\
\hline - Split-dose & $1221(29.1 \%)$ & 2057 (51.1\%) & \\
\hline - Same day & $128(3.1 \%)$ & $177(4.4 \%)$ & \\
\hline \multicolumn{4}{|l|}{ Cleansing regimen according to colonoscopy time, n (\%) } \\
\hline - Colonoscopy before 0930 & & & $<0.0001^{1}$ \\
\hline - Day before & $952(89.3 \%)$ & $629(75.9 \%)$ & \\
\hline - Split-dose & $110(10.3 \%)$ & $197(23.8 \%)$ & \\
\hline - Same day & $4(0.4 \%)$ & $3(0.4 \%)$ & \\
\hline - Colonoscopy $0930-1130$ & & & $<0.0001^{1}$ \\
\hline - Day before & $1061(78.2 \%)$ & $689(53.7 \%)$ & \\
\hline - Split-dose & $290(21.4 \%)$ & $584(45.6 \%)$ & \\
\hline - Same day & $6(0.4 \%)$ & $9(0.7 \%)$ & \\
\hline - Colonoscopy $1130-1400$ & & & $<0.0001^{1}$ \\
\hline - Day before & $456(56.3 \%)$ & $221(30.7 \%)$ & \\
\hline - Split-dose & $328(40.5 \%)$ & $477(66.2 \%)$ & \\
\hline - Same day & $26(3.2 \%)$ & $23(3.2 \%)$ & \\
\hline - Colonoscopy after 1400 & & & $<0.0001^{1}$ \\
\hline - Day before & $149(22.8 \%)$ & $49(7.5 \%)$ & \\
\hline - Split-dose & $425(65.0 \%)$ & $479(73.5 \%)$ & \\
\hline - Same day & $80(12.2 \%)$ & $124(19.0 \%)$ & \\
\hline Modality of communication of cleansing regimen, $\mathrm{n}(\%)^{2}$ & & & 0.193 \\
\hline - Central independent reservation system & $1561(39.6 \%)$ & $1486(39.6 \%)$ & \\
\hline - Module at endoscopic unit & $872(22.1 \%)$ & $816(21.8 \%)$ & \\
\hline - Visit with endoscopic personnel & $536(13.6 \%)$ & $552(14.7 \%)$ & \\
\hline - Other written information & $163(4.1 \%)$ & $141(3.8 \%)$ & \\
\hline - Other oral information & $293(7.4 \%)$ & $243(6.5 \%)$ & \\
\hline - More than one modality & $518(13.1 \%)$ & $510(13.6 \%)$ & \\
\hline \multicolumn{4}{|l|}{ - Proportion of perceived unclear information (\%) } \\
\hline - Central independent reservation system & $6.30 \%$ & $3.90 \%$ & $0.0076^{1}$ \\
\hline - Module at endoscopic unit & $2.60 \%$ & $1.70 \%$ & $0.0415^{1}$ \\
\hline - Visit with endoscopic personnel & $1.30 \%$ & $0.60 \%$ & 0.0607 \\
\hline - Other written information & $8.50 \%$ & $11.40 \%$ & 0.3135 \\
\hline - Other oral information & $13.30 \%$ & $13.20 \%$ & 0.9737 \\
\hline Product used for bowel cleansing, n (\%) & & & $<0.0001^{1}$ \\
\hline - $4 \mathrm{LPEG} \pm$ simethicone & $2396(57.2 \%)$ & $2642(65.7 \%)$ & \\
\hline . 2 L PEG + ascorbate & $1035(24.7 \%)$ & $923(22.9 \%)$ & \\
\hline - Sodium picosulfate / magnesium citrate & $370(8.8 \%)$ & $183(4.5 \%)$ & \\
\hline - 2 L PEG-CS + bisacodyl & $243(5.8 \%)$ & $236(5.9 \%)$ & \\
\hline
\end{tabular}


- Table 3 (Continuation)

\begin{tabular}{|c|c|c|c|}
\hline Variable & Cycle $1(n=4189)$ & Cycle $2(n=4024)$ & $P$ value \\
\hline - Sodium phosphate & $145(3.5 \%)$ & $40(1.0 \%)$ & \\
\hline$\%$ of product consumed, $n(\%)$ & & & $0.0070^{1}$ \\
\hline - $100 \%$ & $3652(87.2 \%)$ & $3585(89.1 \%)$ & \\
\hline . $75-100 \%$ & $457(10.9 \%)$ & $356(8.8 \%)$ & \\
\hline . $<75 \%$ & $80(1.9 \%)$ & $83(2.1 \%)$ & \\
\hline Mean regimen length $(S D)$, hours & $8.60(6.46)$ & $10.00(5.84)$ & $<0.0001^{1}$ \\
\hline Mean preparation-to-colonoscopy interval (SD), hours ${ }^{3}$ & $10.93(4.93)$ & $8.55(4.97)$ & $<0.0001^{1}$ \\
\hline Preparation-to-colonoscopy interval (categorical) ${ }^{3}$ & & & $<0.0001^{1}$ \\
\hline . $<3$ hours & $188(5.1 \%)$ & $300(9.0 \%)$ & \\
\hline - 3-4 hours & $241(6.5 \%)$ & $387(11.6 \%)$ & \\
\hline - 4-5 hours & $270(7.3 \%)$ & $466(14.0 \%)$ & \\
\hline . $5-6$ hours & $219(5.9 \%)$ & $297(8.9 \%)$ & \\
\hline - $\geq 6$ hours & $2793(75.3 \%)$ & $1877(56.4 \%)$ & \\
\hline Means of transport to reach the hospital (outpatients), $\mathrm{n}(\%)^{4}$ & & & $<0.0001^{1}$ \\
\hline - Private & 3427 (93.1\%) & 3409 (95.3\%) & \\
\hline - Public & $253(6.9 \%)$ & $170(4.7 \%)$ & \\
\hline Patients willing to repeat the same preparation, $\mathrm{n}(\%)$ & $3369(80.4 \%)$ & $3342(83.1 \%)$ & $0.0021^{1}$ \\
\hline \multicolumn{4}{|c|}{$\begin{array}{l}\text { SD, standard deviation. } \\
1 P<0.05 \text {. } \\
2 \text { Percentages are referred to the total number of patients with available information }(n=3943 \text { for Cycle } 1 \text { and } 3748 \text { for Cycle 2). } \\
{ }^{3} \text { Length and percentages are referred to the total number of patients with available information ( } n=3711 \text { for Cycle } 1 \text { and } 3327 \text { for Cycle 2). } \\
{ }^{4} \text { Percentages are referred to the total number of outpatients }(n=3680) \text {. }\end{array}$} \\
\hline
\end{tabular}

8.4]), respectively. Considering as reference those patients receiving the cleansing regimen by the independent central reservation system, the information being provided by the endoscopy unit through a module and, even more, through a visit with endoscopy personnel significantly increased the probability of adopting a split-dose regimen $(\mathrm{OR}=1.6[\mathrm{Cl} 1.3-$ 1.9] for the module and $\mathrm{OR}=2.1[\mathrm{Cl} 1.7-2.5]$ for the visit), as well as the information being provided through more than one modality $(\mathrm{OR}=2.8[\mathrm{Cl} 2.3-3.3])$. A split-dose regimen was less likely to be adopted when colonoscopy was planned under deep sedation ( $\mathrm{OR}=0.5$ vs no sedation, $\mathrm{Cl} 0.4-0.6)$, and when the patient had a higher education level (secondary vs primary: $\mathrm{OR}=0.8[\mathrm{Cl} 0.6-0.9]$ and degree vs primary: $\mathrm{OR}=0.8[\mathrm{Cl} 0.7-$ $0.99])$, while it was more probable if colonoscopy was the first $(\mathrm{OR}=1.3[\mathrm{Cl} 1.1-1.5])$, was prescribed by a gastroenterologist rather than a general practitioner $(\mathrm{OR}=1.3[\mathrm{Cl} 1.1-1.5])$, and for screening rather than for surveillance $(O R=1.3[\mathrm{Cl} 1.1-$ 1.5]). No influence of sex, comorbidities, or inpatient vs outpatient status was found. Being enrolled in Cycle 2 was an independent variable associated with an almost 3 -fold increased probability of split-dose regimen adoption $(\mathrm{OR}=2.9 ; \mathrm{Cl} 2.6$ 3.3).

Other multivariate models. Other multivariate logistic regression models (dependent variables: adoption of a split-dose or a same-day regimen for afternoon colonoscopies; patients' willingness to repeat the preparation; endoscopist satisfaction about bowel cleansing; adequate preparation of left and right colon) are described in Supplementary Tables 1, 2, 3, 4, and 5. A split-dose regimen was an independent predictor of cleansing adequacy, endoscopist satisfaction, and patient willingness to repeat the regimen.

\section{Discussion}

According to our study, including 8213 patients, a nationwide implementation of the PDSA approach was able to almost double the rate of split-dose regimen adoption. In addition, such an approach significantly decreased the "runway time", a known strong predictor of better bowel preparation [19]. Of note, most of the interventions applied between the two cycles were simple organizational changes, not requiring any technological or economic effort.

We believe that the results of our study are relevant for the following reasons.

First of all, despite the split-dose regimen being recommended by different guidelines [5, 6], being associated with better bowel cleansing [1, 2], and yielding a higher detection of colonic lesions [3,4], the current adoption of this regimen is still disappointing. For instance, in our study, almost $70 \%$ of colo- 
- Table 4 Colonoscopies: description of preprocedural and intraprocedural variables.

\begin{tabular}{|c|c|c|c|}
\hline Variable & Cycle $1(n=4189)$ & Cycle $2(n=4024)$ & $P$ value \\
\hline First colonoscopy, n (\%) & $2233(53.3 \%)$ & $2282(56.7 \%)$ & $0.0019^{1}$ \\
\hline Indication for colonoscopy, n (\%) & & & 0.1692 \\
\hline - Follow-up & $1214(29.0 \%)$ & $1101(27.4 \%)$ & \\
\hline - Screening & $1056(25.2 \%)$ & $1072(26.6 \%)$ & \\
\hline - Symptoms & $1918(45.8 \%)$ & $1851(46.0 \%)$ & \\
\hline Prescriber, n (\%) & & & $0.0010^{1}$ \\
\hline . GP & $1848(44.1 \%)$ & $1669(41.5 \%)$ & \\
\hline - Gastroenterologist & $1332(31.8 \%)$ & $1436(35.7 \%)$ & \\
\hline - Other specialist & $1008(24.1 \%)$ & $919(22.8 \%)$ & \\
\hline Sedation, $\mathrm{n}(\%)$ & & & $0.0005^{1}$ \\
\hline - None & $1304(31.1 \%)$ & $1165(29.0 \%)$ & \\
\hline - Conscious & $2448(58.5 \%)$ & $2511(62.4 \%)$ & \\
\hline - Deep & $436(10.4 \%)$ & $348(8.6 \%)$ & \\
\hline Scheduled colonoscopy time, n (\%) & & & $0.0019^{1}$ \\
\hline - Before 0930 & $1066(27.4 \%)$ & $829(23.8 \%)$ & \\
\hline . $0930-1130$ & $1357(34.9 \%)$ & $1282(36.8 \%)$ & \\
\hline . $1130-1400$ & $810(20.8 \%)$ & $721(20.7 \%)$ & \\
\hline - After 1400 & $654(16.8 \%)$ & $652(18.7 \%)$ & \\
\hline Cecal intubation, $\mathrm{n}(\%)$ & $3784(90.4 \%)$ & $3679(91.4 \%)$ & 0.0913 \\
\hline Right colon cleansing, n (\%) & & & $0.0274^{1}$ \\
\hline - Adequate & $3224(77.1 \%)$ & $3184(79.1 \%)$ & \\
\hline - Not adequate & $957(22.9 \%)$ & $840(20.9 \%)$ & \\
\hline Left colon cleansing, $\mathrm{n}(\%)$ & & & $<0.0001^{1}$ \\
\hline - Adequate & $3645(87.1 \%)$ & $3619(89.9 \%)$ & \\
\hline - Not adequate & $539(12.9 \%)$ & $405(10.1 \%)$ & \\
\hline Endoscopist satisfied with bowel cleansing, n (\%) & & & $0.0197^{1}$ \\
\hline - Yes & $3288(78.6 \%)$ & $3245(80.6 \%)$ & \\
\hline - No & $897(21.4 \%)$ & $779(19.4 \%)$ & \\
\hline
\end{tabular}

noscopies were not prepared using a split-dose regimen during Cycle 1.

Second, we demonstrated that a simple auditing of bowel cleansing in two phases separated by an educational intervention was sufficient to stimulate spontaneous local interventions determining a significant increase in split-dose regimen adoption. This was not unexpected as the PDSA approach has already proven its efficacy in other areas of bowel cleansing improvement $[13,14,18]$. Of note, the PDSA approach has no direct costs related to the model itself. The indirect costs linked to the eventual diffusion of educational material or to the time spent in the process are not expected to represent a significant burden in an era in which hospital administrations actively sustain actions involved in quality improvement.

Third, we found that such an improvement was mainly obtained through local organizational skills. Colonoscopies scheduled after 0930 and a more careful use of deep sedation significantly increased the probability of split-dose regimen adoption. These factors suggest that it could be simpler for endoscopy facilities to take care of these center-related factors, instead of promoting resource-consuming interventions such as the development of booklets or mobile phone applications, the use of short message services (SMS), or hiring navigators [13, 20 22]. 
- Table 5 Multivariate logistic regression model: predictors of the adoption of a split-dose versus a day-before regimen. Results are expressed as odds ratio (OR) and $95 \%$ confidence interval $(\mathrm{Cl})$. For this model, afternoon colonoscopies were excluded and 5994 observations were used.

\begin{tabular}{|c|c|c|c|}
\hline Variable & Odds Ratio & $95 \%$ Confidence interval & $P$ value \\
\hline Cycle 1 & 1 & & $<0.0001$ \\
\hline Cycle 2 & 2.923 & $2.583-3.311$ & \\
\hline Scheduled time for colonoscopy & & & $<0.0001$ \\
\hline - Before 0930 & 1 & & \\
\hline - $0930-1130$ & 2.637 & $2.259-3.080$ & \\
\hline - $1130-1400$ & 7.036 & $5.924-8.357$ & \\
\hline Communication of bowel cleansing & & & $<0.0001$ \\
\hline - Independent reservation system & 1 & & \\
\hline - Form from the Endoscopy unit & 1.57 & $1.323-1.863$ & \\
\hline - Visit with Endoscopy personnel & 2.087 & $1.715-2.540$ & \\
\hline - Other written information & 0.481 & $0.329-0.702$ & \\
\hline - Other oral information & 1.284 & $0.987-1.670$ & \\
\hline - More than one modality & 2.752 & $2.290-3.308$ & \\
\hline - Missing information & 0.512 & $0.289-0.908$ & \\
\hline Sedation & & & $<0.0001$ \\
\hline - None & 1 & & \\
\hline - Conscious & 0.985 & $0.858-1.131$ & \\
\hline - Deep & 0.5 & $0.391-0.640$ & \\
\hline First colonoscopy & 1.281 & $1.115-1.472$ & $<0.0001$ \\
\hline Prescriber of the colonoscopy & & & 0.0001 \\
\hline - General practitioner & 1 & & \\
\hline - Gastroenterologist & 1.314 & $1.136-1.519$ & \\
\hline - Other specialist & 0.913 & $0.774-1.076$ & \\
\hline Product used for bowel cleansing & & & 0.0005 \\
\hline - $4 \mathrm{~L}$ PEG \pm simethicone & 1 & & \\
\hline - $2 \mathrm{LPEG}+$ ascorbate & 1.025 & $0.881-1.193$ & \\
\hline - 2 LPEG + citrate + bisacodyl & 0.55 & $0.408-0.741$ & \\
\hline - Magnesium citrate + sodium picosulfate & 0.896 & $0.697-1.152$ & \\
\hline - Sodium phosphate & 1.218 & $0.820-1.810$ & \\
\hline Education & & & 0.006 \\
\hline - Primary & 1 & & \\
\hline - Secondary I & 0.958 & $0.804-1.141$ & \\
\hline - Secondary ll & 0.761 & $0.642-0.902$ & \\
\hline - Degree or above & 0.803 & $0.655-0.986$ & \\
\hline Indication for colonoscopy & & & 0.0091 \\
\hline - Surveillance & 1 & & \\
\hline - Screening & 1.255 & $1.047-1.504$ & \\
\hline - Symptoms & 1.013 & $0.859-1.195$ & \\
\hline
\end{tabular}


Fourth, despite the PDSA-driven implementation, at the end of our study, more than $40 \%$ of colonoscopies were still being prepared through the day-before regimen. In this scenario, analyses of barriers opposing adherence to a split-dose regimen are relevant, particularly in the setting of morning colonoscopies, for which this modality is recommended and its adoption most challenging. In our study, to our knowledge the largest analyzing this outcome, early morning colonoscopies, deep sedation, and a higher patient educational level were negatively associated with split-dose regimen adoption, whereas the regimen being communicated by the endoscopy unit, the colonoscopy being the first one, being prescribed for screening and by a gastroenterologist were all associated with a higher probability of split-dose regimen adoption. This adds to previous experiences analyzing barriers against a split-dose regimen [10, 11].

As a consequence, some areas of intervention may be deduced. The role of patient-related factors must not be underestimated: the fact that, in our study, a higher educational level was associated with a reduced probability of split adoption could probably suggest that these patients are less prone to passively receive instructions, may feel more at liberty to deviate from protocols, may be looking for a second opinion (e.g. pharmacist, previous users, general practitioner), or for additional information (e.g. internet), and this could represent a barrier when this claim for involvement meets low-quality information, as already demonstrated [11], especially in a period of changing practices. However, it can be reasonably assumed that a higher cultural level could eventually represent fertile ground for educational interventions, if the advantages of a split dose regimen are adequately and exhaustively explained. In any case, our data indicate that organizational factors are likely to play a pivotal and major role in overcoming other individual barriers. For example, even if an amelioration in splitdose regimen adoption was also achieved for colonoscopies before 0930 , preferring to schedule upper endoscopies or rectosigmoidoscopies in early morning slots could represent a significant intervention to optimize bowel cleansing. However, it is not just endoscopists who have a role in this improvement. For example, even though studies have demonstrated that residual gastric volume is not higher with a split-dose regimen when the last dose of preparation is consumed at least 3 hours before the colonoscopy [23-26], in our study, anesthesiological concerns seem to be relevant in hampering the adoption of a split-dose regimen.

Our study has several limitations. First, patients in Cycle 1 and Cycle 2 were not matched; however, no demographical differences were observed between the two groups apart from the slightly higher prevalence of comorbidities in Cycle 2. This is reassuring as it did not affect the possibility to improve splitdose regimen adoption. Second, we did not survey the rate of bowel movements or the need for travel interruption while reaching the endoscopy unit, but the higher prevalence of patients willing to repeat the same preparation in Cycle 2 (with split-dose regimen predicting this willingness in multivariate analyses) lowers the suspicion of split-dose-related unpleasant events. Third, we detected only a slight improvement in bowel cleansing adequacy after the intervention; however, since this was not the primary outcome, it was subjectively and unblindely evaluated as "adequate" or "not adequate" without the use of a validated scale and without investigating potentially relevant confounding factors (e.g. drugs such as antidepressants or opioids, comorbidity scores, previous bowel regularity, etc.), and therefore, the multivariate analysis of Supplementary Tables $\mathbf{4}$ and $\mathbf{5}$ must take into account these concerns; however, the efficacy of split-dose regimens in improving major outcomes (i.e. bowel cleansing, right colon cleansing, polyp, adenoma, and advanced adenoma detection rates, etc.) has been extensively and firmly demonstrated [1-4], and therefore, the low magnitude of bowel cleansing improvement in this study must be attributed exclusively to the non-standardized method we used to measure this outcome. Fourth, iteration of intermediate short cycles exploring single interventions is theoretically missing in our study as well as in the majority of published studies using a PDSA approach [17]; however, we tried to compensate for this by conducting a multivariate analysis deducing the main factors driving the changes in splitdose regimen adoption, most likely reflecting those to focus on during future clinical practice or research. Finally, interventions between the two cycles were not preordered or fixed, but such a flexible approach was nevertheless successful, further reassuring us about the generalizability of the method, which lends itself well to the variability of the volumes, setting, and expertise of different local facilities. Of note, the participating centers included both academic and non-academic centers, and even a small proportion of private facilities.

Despite all these limitations, to our knowledge, this is the largest study targeting an improvement in split-dose regimen adoption, the first to use the PDSA approach with this aim, and the only study addressing this goal on an unselected population (regardless of age, comorbidities, indication for colonoscopy, inpatient versus outpatient status, etc.). Although the study was not meant to evaluate the efficacy of specific interventions, we have highlighted a number of factors significantly favoring or limiting split-dose regimen adoption, potentially steering further research on this topic. A PDSA approach, through awareness of the problem, attention to quality improvement, and creation of feedback, has led to a doubling of split-dose regimen adoption in the participating centers.

\section{Participating centers}

Coordinating Centre: Endoscopy Unit, Sant'Andrea Hospital, Faculty of Medicine and Psychology, Sapienza, University of Rome. For the complete list of participating centers, please see Supplementary Material, Statement 3.

\section{Acknowledgments}

The authors would like to remember with heartfelt gratitude their friend Gianluca Rotondano, recently deceased, whose contribution has been decisive for the realization of this project. The study was economically supported by an uncondition- 
al grant from Alfasigma, Bologna, Italy, without any involvement in study design and data analysis.

\section{Competing interests}

\section{None}

\section{References}

[1] Bucci C, Rotondano G, Hassan C et al. Optimal bowel cleansing for colonoscopy: split the dose! A series of meta-analyses of controlled studies Gastrointest Endosc 2014; 80: 566 - 576.e2

[2] Martel M, Barkun AN, Menard C et al. Split-dose preparations are superior to day-before bowel cleansing regimens: A meta-analysis. Gastroenterology 2015; 149: 79-88

[3] Radaelli F, Paggi S, Hassan C et al. Split-dose preparation for colonoscopy increases adenoma detection rate: a randomised controlled trial in an organised screening programme. Gut 2017; 66: $270-277$

[4] Jover R, Zapater P, Polanía E et al. Modifiable endoscopic factors that influence the adenoma detection rate in colorectal cancer screening colonoscopies. Gastrointest Endosc 2013; 77: 381 - 389.e1

[5] Hassan C, Bretthauer M, Kaminski MF et al. Bowel preparation for colonoscopy: European Society of Gastrointestinal Endoscopy (ESGE) guideline. Endoscopy 2013; 45: 142 - 150

[6] Saltzman JR, Cash BD et al. ASGE Standards of Practice Committee JR. Bowel preparation before colonoscopy. Gastrointest Endosc 2015; 81: $781-794$

[7] Woo DH, Kim KO, Jeong DE et al. Prospective analysis of factors associated with inadequate bowel preparation for colonoscopy in actual clinical practice. Intest Res 2018; 16: $293-298$

[8] Rembacken B, Hassan C, Riemann JF et al. Quality in screening colonoscopy: position statement of the European Society of Gastrointestinal Endoscopy (ESGE). Endoscopy 2012; 44: 957 - 968

[9] Johnson DA, Barkun AN, Cohen LB et al. Optimizing adequacy of bowel cleansing for colonoscopy: recommendations from the U.S. Multi-Society Task Force on Colorectal Cancer. Gastrointest Endosc 2014; 80: 543- 562

[10] Menees SB, Kim HM, Wren P et al. Patient compliance and suboptimal bowel preparation with split-dose bowel regimen in average-risk screening colonoscopy. Gastrointest Endosc 2014; 79: 811-820.e3

[11] Radaelli F, Paggi S, Repici A et al. Barriers against split-dose bowel preparation for colonoscopy. Gut 2017; 66: 1428-1433

[12] Andrealli A, Paggi S, Amato A et al. Educational strategies for colonoscopy bowel prep overcome barriers against split-dosing: A ran- domized controlled trial. United Eur Gastroenterol J 2018; 6: 283 289

[13] Calderwood AH, Mahoney EM, Jacobson BC. A Plan-Do-Study-Act approach to improving bowel preparation quality. Am J Med Qual 2017; 32: $194-200$

[14] Shah-Khan SM, Cumberledge J, Reynolds G]. Using the Plan-Do-StudyAct approach to improve inpatient colonoscopy preparation. BM] Open Qual 2017; 6: e000230

[15] Langley G, Moen R, Nolan K et al. The improvement guide: a practical approach to enhancing organizational performance. San Francisco: Jossey-Bass Publishers; 2009

[16] Kheraj R, Tewani SK, Ketwaroo G et al. Quality improvement in gastroenterology clinical practice. Clin Gastroenterol Hepatol 2012; 10 : $1305-1314$

[17] Taylor M], McNicholas C, Nicolay C et al. Systematic review of the application of the plan-do-study-act method to improve quality in healthcare. BMJ Qual Saf 2014; 23: $290-298$

[18] Srisarajivakul N, Chua D, Williams R et al. How we cleaned it up: A simple method that improved our practice's bowel prep. Am J Gastroenterol 2016; 111: 1079-1081

[19] Siddiqui AA, Yang K, Spechler SJ et al. Duration of the interval between the completion of bowel preparation and the start of colonoscopy predicts bowel-preparation quality. Gastrointest Endosc 2009; 69: $700-706$

[20] Walter B, Klare P, Strehle K et al. Improving the quality and acceptance of colonoscopy preparation by reinforced patient education with short message service: results from a randomized, multicenter study (PERICLES-II). Gastrointest Endosc 2019; 89: 506 -513.e4

[21] Spiegel BMR, Talley J, Shekelle P et al. Development and validation of a novel patient educational booklet to enhance colonoscopy preparation. Am J Gastroenterol 2011; 106: 875-883

[22] Sharara Al, Chalhoub JM, Beydoun M et al. A customized mobile application in colonoscopy preparation: A randomized controlled trial. Clin Transl Gastroenterol 2017; 8: e211

[23] Xue S, Chen H, Cheng C et al. Gastric residual volume after split-dose bowel preparation versus conventional single-dose regimen before anesthetic colonoscopy. Biomed Res Int 2017; 2017: 1-4

[24] Agrawal D, Elsbernd B, Singal AG et al. Gastric residual volume after split-dose compared with evening-before polyethylene glycol bowel preparation. Gastrointest Endosc 2016; 83: 574-580

[25] Huffman M, Unger RZ, Thatikonda C et al. Split-dose bowel preparation for colonoscopy and residual gastric fluid volume: an observational study. Gastrointest Endosc 2010; 72: 516-522

[26] Alghamry A, Ponnuswamy SK, Agarwal A et al. Split-dose bowel preparation with polyethylene glycol for colonoscopy performed under propofol sedation. Is there an optimal timing? J Dig Dis 2017; 18: $160-168$ 